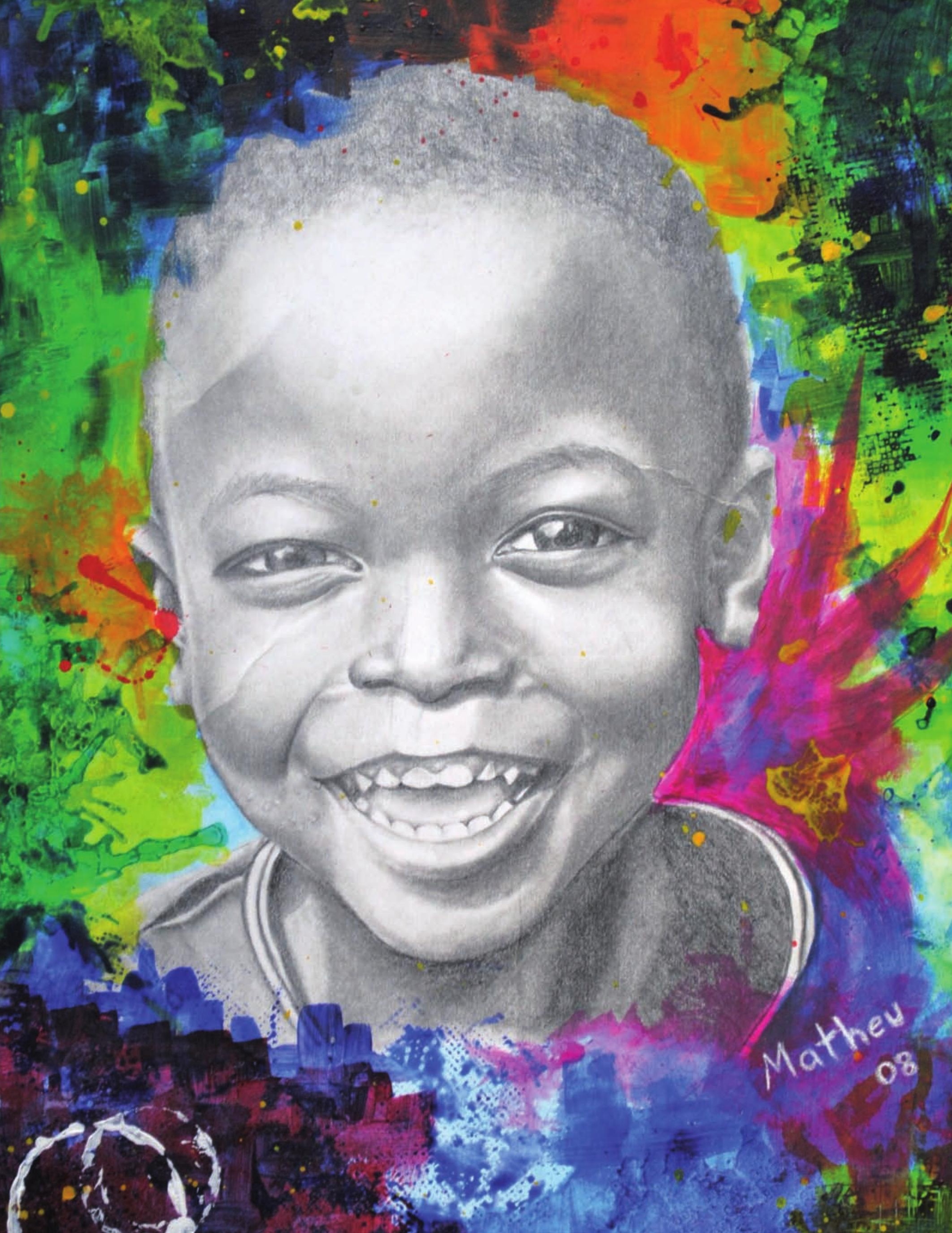




\section{Descalzos, sin pan y en petate preguntas especiales en el censo de población de Honduras de 1950}

Manuel Antonio Flores Fonseca*

RESUMEN. La mitad del siglo pasado marca el inicio de una nueva perspectiva nacional, recién se salía de una larga dictadura y cualquier iniciativa gubernamental sería vista como un adelanto, aparte de que las condiciones del país denotaban un atraso al compararlo con otros países. La creación y reorganización de instituciones estatales vislumbra el nacimiento del estado moderno, entre estas la Dirección General de Censos y Estadísticas que lleva cabo un censo de población, sumándose a una iniciativa regional.

El título sugestivo de este ensayo es la descripción sencilla de las cifras del Censo General de Población de Honduras de 1950 de tres preguntas que se consideran especiales, el uso del calzado, el consumo de pan de trigo y la clase de adminículo utilizado para dormir.

Los resultados censales muestran que la población hondureña en su mayoría no usaba calzado, tenía un bajo consumo de pan de trigo, aunque este alimento no ha sido tradicional en la dieta de la población y por otro lado la masiva utilización del tradicional "petate". Los datos describen las condiciones de vida de la población en aspectos tan sensibles de la vida humana como el andar, la alimentación y el descanso.

Palabras claves: trigo, petate, calzado.

\section{INTRODUCCION}

La mitad del siglo pasado representó para el país un período importante en la vida republicana, esto porque recién había dejado atrás muchos años de gobernanza dictatorial que incidió en las nuevas autoridades para el desarrollo de una mejor estructuración del Estado hondureño.

Asimismo, la creación o reforma institucional llevó a la necesidad de contar con información actual de la población hondureña, en ese sentido, se lleva a cabo la elaboración del censo general de población, uniéndose al proyecto regional del censo de las Américas, siguiendo las recomendaciones internacionales.

Este título tan sugestivo de este ensayo representa solamente la descripción más sencilla de las cifras del Censo General de Población de Honduras de 1950, acerca de tres preguntas que se consideran especiales y que incluso nunca se volvieron a formular en ningún recuento censal en el país: el uso del calzado, el consumo de pan de trigo y la clase de adminículo utilizado para dormir.

En los resultados censales se observa que la población hondureña en su mayoría no usaba calzado, tenía un bajo consumo de pan de trigo, aunque este alimento no ha sido tradicional en la dieta de la población y por otro lado la masiva utilización del tradicional "petate" tapete de tejido vegetal en los adminículos para dormir. Estos resultados describen en general algunas de las condiciones de vida de la población hondureña en aspectos tan sensibles de la vida humana como el andar, la alimentación y el descanso.

\section{ANTECEDENTES}

Honduras se declara independiente del reino de España desde 1821, se conformó como una republica 
escasamente poblada, siguiendo patrones de asentamientos heredados de la época precolombina y colonial, eminentemente rural y con una economía basada en la producción agropecuaria. Es hasta finales del siglo XIX que la Reforma Liberal hace que se sienten las bases de una estructuración como nación, con acciones de carácter institucional para permitir el ingreso de capital foráneo en algunas áreas económicas como la minería, la agricultura y la industria e intentar la inserción del país en el mercado mundial. El nuevo siglo aumentó la presencia extranjera en forma de enclave y enfocada en rubros agrícolas específicos, como el banano, que llevaron a considerar al país a través del tiempo como una república bananera. $\mathrm{Al}$ mismo tiempo muchos años de guerras intestinas en la disputa del poder, desembocan en la llegada al poder del caudillo Carías que se perpetuó en el poder varios años (1933-1948).

Al mismo tiempo en los años cincuenta asoman potencialidades y deficiencias del país, algunas signos de atraso se manifiestan en una insuficiente infraestructura vial (una de las más bajas de la región), baja generación de energía eléctrica (la menor del hemisferio occidental a excepción de Haití), bajos niveles de educación de la población, escaso acceso a la salud pública por la población que es afectada por malaria, infecciones pulmonares e intestinales, una dieta alimenticia limitada en cantidad y deficiente en muchas vitaminas donde la mayoría de la población vive de frijoles, arroz y maíz, en general las condiciones de vida de la población hondureña son deplorables en ese tiempo (Checchi y Ass, 1959).

En la segunda mitad del siglo pasado se presenció la aceleración de un proceso de modernización. Asume la administración del Estado Juan Manuel Gálvez (1949. 1954), que fue ministro de guerra de Carías y abogado de la United Fruit Company, a través de elecciones sin contrincantes. Su programa enfatiza en el desarrollo de la agricultura y se requería una extensa red vial, carreteras y la promoción de cultivos del azúcar, café, algodón, ajonjolí, bananos y madera. Complementaban su política la creación de nuevas instituciones estatales para regular la economía y una apertura política con antecedentes en los acuerdos con el Banco Mundial y el Fondo Monetario Internacional, quienes asesoraron el plan que dio como fruto en 1950 la creación del Banco Central de Honduras y el Banco Nacional de Fomento (Barahona, 2005).

A partir de 1950 se perfilan cambios institucionales, económicos y sociales. Fue creciendo el valor y la importancia del sector público: fundación de la banca estatal; diversificación económica (azúcar, carne, café, algodón, palma africana entre otros); creación del impuesto sobre la renta, otorgamiento de asistencia técnica y crediticia a ganaderos, agricultores; campañas educativas y sanitarias. Toda esta expansión estatal fue posible por los préstamos contraídos con los organismos internacionales de crédito. El sector privado contempló un crecimiento significativo: en la manufactura, construcción, comercio y banca. El movimiento cooperativo también se expandió bajo la guía de la Dirección de Fomento Cooperativo.

Asimismo, la producción o elaboración de algunos productos de consumo o uso habitual en las poblaciones como el calzado, la elaboración de pan de trigo y la elaboración de camas evolucionaron a través del tiempo y hay que contextualizarla en los años cincuenta.

La producción de calzado en el país se caracterizaba por ser de tipo artesanal a nivel familiar y su desarrollo fue muy lento aún con el surgimiento de empresas de la industria del calzado como la Fábrica Nacional de Suelas y Zapatos Naco, en la ciudad de La Ceiba y otra empresa La Flecha en la ciudad de Tegucigalpa. La fábrica Naco surgió en 1921, siendo la primera empresa industrial de calzado en Honduras dedicada a la fabricación de calzado de hombre y niño y a la fabricación de suela. Fue la más importante empresa del calzado equipada con maquinaria moderna en su tiempo, aunque debía importar todos los materiales incluyendo el cuero. El volumen de calzado importado en 1956 fue el doble del importado en 1951 y casi cuatro veces más grande del importado en 1945 (Checchi y Ass, 1959). La fábrica Naco cerró operaciones en 1966 por deficiencia administrativas. A raíz de la falta de materias primas 
y para resolver problemas comunes en 1950 se creó la Cooperativa La Fraternidad.

La molinería del trigo en Honduras se remonta al año 1930 con la constitución de la sociedad Molino Hondureño, S.A. Este fue el primer molino de trigo que existió en el país, siendo sus socios fundadores los Señores Magnus Zeppelín, Otto Behn y William Bennaton, de origen alemán y hondureño. Esta fábrica se encontraba localizada en San Pedro Sula. El Molino Hondureño S.A. operaba con un molino de trigo marca" Midget Marcel" de 100 barriles, movido por un motor diesel "Fairbank Morse", ambos de fabricación norteamericana; su capacidad de molienda alcanzaba la cantidad de hasta 180 quintales de producción de harina de trigo en un período de 24 horas.

A principio de los años cuarenta inició operaciones en Tegucigalpa otro molino que llevaba por nombre Molino Central Harinero S.A. que operaba con una maquinaria de origen italiano marca "Golfetto" y que producía 90,000 quintales anuales.

En esa época, el trigo y material de empaque era importado de los Estados Unidos de Norte América. Los sacos en que venía el trigo eran de Yute y contenían 180 libras cada uno, ya que en dicho tiempo no se importaba el mismo a granel como en la actualidad se hace. El trigo era transportado hasta Puerto Cortés vía marítima por la United Fruit Company y de allí a San Pedro Sula haciendo uso del Ferrocarril Nacional y contaba con el servicio de un switch ferroviario exclusivo muy cerca de sus bodegas lo que les permitía acarrear los sacos de trigo de los vagones del tren hacia sus bodegas y silos con pequeños trocos en los que se movilizaban hasta 30 sacos de una sola vez. En aquellos tiempos su capacidad de almacenaje entre bodegas y silos era de 15,000 bushels o sea 900,000 libras de trigo ya que cada bushel es igual a 60 libras.

Molino Harinero Sula, S.A. (M.H.S.), surge el 8 de Noviembre de 1946. El primer molino que operó el Molino Harinero Sula, S.A., el cual se ubicó en el Barrio La Guardia donde actualmente se encuentra el Molino Hondureño S.A. era marca "Robinson" de fabricación inglesa, con capacidad de molienda de 300 a 350 quintales de harina diarios. Las marcas de harina que se elabora- ban en esta fábrica eran "El Águila", desde el inicio de operaciones, y "La Cumbre", desde a mediados de 1956. "El Águila" se utilizaba para la elaboración de tortillas y panes dulces en general y "La Cumbre” por ser más fina y suave para hacer galletas y pasteles. Las marcas de harina "El Gallo" y "La Rosa”, que también eran y son harinas semifuertes, han sido siempre marcas propias de Molino Harinero Sula, S.A. Es hasta en el año 1959 que Molino Harinero Sula, S.A. empieza a producir "El Panadero", una harina fuerte para elaborar pan blanco. En el año de 1960 acordaron fusionarse Molino Harinero Sula, S.A. con Molino Hondureño S.A.

En aquellos tiempos el mercado nacional estaba saturado de harinas importadas principalmente de los Estados Unidos como ser la marca "Gold Medal" y "Swan Dawn". Todas las harinas producidas en aquella época tanto por Molino Harinero Sula, S.A. como por Molino Hondureño S.A., se empacaban en sacos de yute de $25 \mathrm{lb}, 50 \mathrm{lb}$ y eran vendidas al por mayor en todas las direcciones del territorio nacional donde era viable el acceso, haciendo uso de las nuevas facilidades que en aquel entonces propiciaban las vías ferroviarias de la costa norte y carretera de tierra hacia la capital de la República.

Antes de este período, en el cual se contaba con escasas facilidades de comunicación terrestre, la mayor parte de su producción era vendida en el mercado local y la distribución se hacía por medio de carretas de mulas, aparte que también muchos comerciantes ambulatorios, a los que en aquel tiempo se les conocía con el nombre de "Arrieros", que viajaban de pueblo en pueblo vendiendo varios productos, y que los transportaban a lomo de mula, compraban al semi-mayoreo para distribuir la harina en los distintos pueblos y caseríos por donde ellos pasaban (Molino Harinero Sula. Historia. www.molinoharinerosula.com).

\section{FUENTE DE DATOS}

La principal fuente de datos en esta investigación es el Censo de Población de 1950, considerado el tredécimo elaborado en el país, que hasta ese momento censal sólo había llevado a cabo censos de facto. ${ }^{1}$ Este censo se realizó 
en la administración gubernamental del Dr. Juan Manuel Gálvez, en una etapa de transición donde recién la institución rectora de la estadística nacional fue reorganizada con criterios modernos. Asimismo, se levantó en un año en el cual los países de la región latinoamericana habrían decidido llevar a cabo una operación censal que lograra comparación internacional.

La boleta censal contiene una sola página con múltiples líneas, siendo una boleta única, con un mínimo de contenidos recomendado por la Comisión del Censo de las Américas (COTA), incluyendo 19 preguntas referentes a las características socioeconómicas de las personas, ${ }^{2}$ entre ellas las características de las personas como relación de parentesco, la edad, sexo, estado civil, lugar de nacimiento, nacionalidad, domicilio, las características económicas de las personas como la profesión u oficio, ocupación, rama de actividad, posición dentro de la ocupación, antigüedad en el trabajo, motivo por el que no trabaja. Asimismo, se incluyeron tres preguntas especiales acerca del uso de calzado, consumo de pan de trigo y adminículos donde duermen las personas.

La operación censal fue dirigida por el Director de Estadística, los jefes departamentales y municipales fueron designados por tradición censal por los goberna- dores políticos, los Jefes de Distrito o Alcaldes. En cada municipio se designaron por un mes dos jefes de empadronadores, mismos que con los empadronadores fueron escogidos entre personas que tenían cierta preparación para esa tarea y fueron instruidos en breves cursos y mediante instrucciones escritas. Los oficiales y el personal de campo trabajaron ad honorem considerándose un deber patriótico esa colaboración.

Las etapas preparatorias del censo no incluyeron un censo de prueba, solamente pruebas de la boleta. El empadronamiento se llevó a cabo en un día en las áreas urbanas y cuatro en área rurales, siendo el momento censal el 18 de junio de 1950. Se utilizaron un aproximado de 12,000 empadronadores y en cada Distrito o Municipio se publicó un bando en el cual se informaba que el día del censo ningún habitante podría salir de casa de las 7 de la mañana a las 5 de la tarde conminado por penas a los infractores. En la etapa post censal la información fue tabulada manualmente. El costo total del censo fue de 51,300 lempiras, siendo el costo unitario de 0.04 centavos de lempira por habitante.

Respecto a la calidad de la información el censo de población indica que la omisión censal fue alrededor del $7 \%$. Los principales errores de enumeración se produjeron

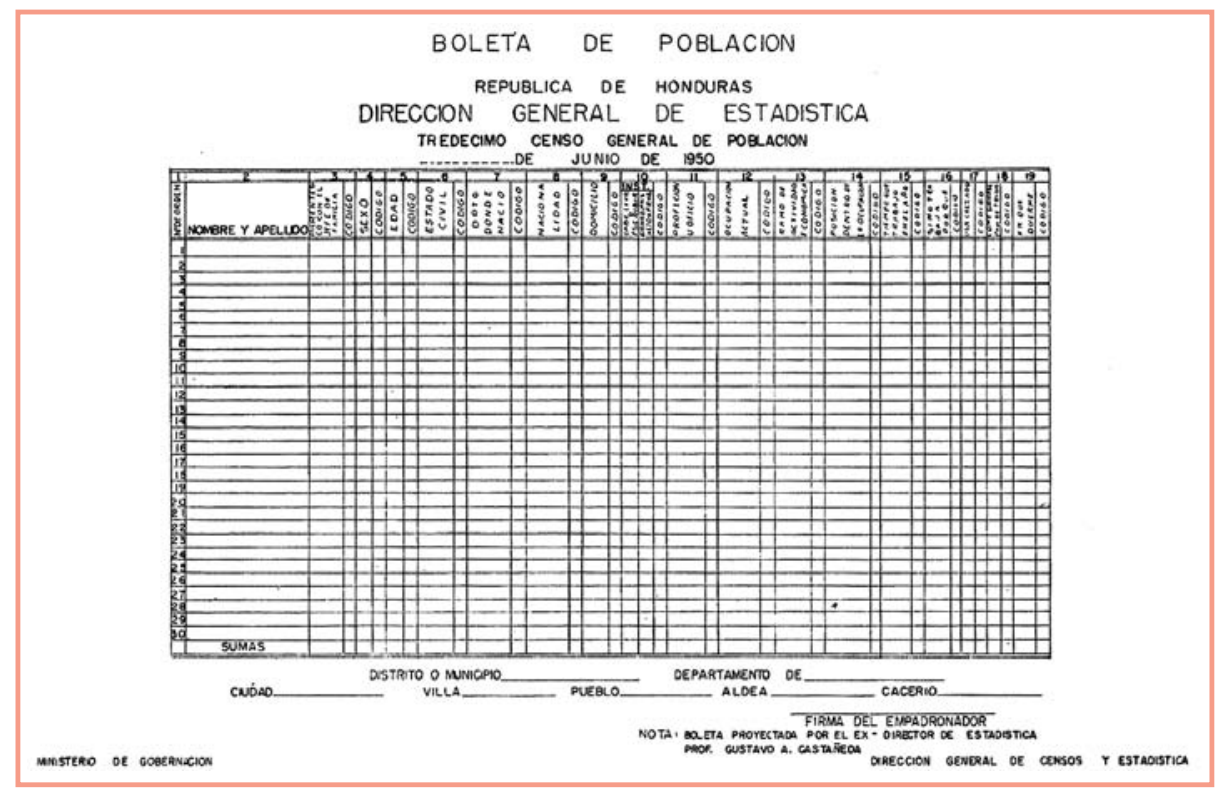

1. Censo de Facto empadrona a las personas en el lugar donde se encuentran en el momento censal.

2. No incluye preguntas de las características de las viviendas porque en 1949 se realizó un Censo de Viviendas que resulta ser el pre censo de población. 
en las preguntas de actividad económica, misma que fue ajustada tomando en cuenta la información atinente del Banco Central y del Banco Nacional de Fomento. Como la operación censal fue eminentemente manual los resultados generalmente fueron frecuencias y en algunos caso tabulaciones cruzadas por sexo y edad.

\section{ANÁLISIS DE DATOS}

\subsection{Resultados Generales}

El Censo de Población de 1950 presenta resultados nacionales de un total de 1,368,605 habitantes, de los cuales el $87 \%$ residía en poblados de menos de dos mil habitantes. La densidad demográfica alcanzaba los 12.2 habitantes por kilómetro cuadrado. En el área rural ${ }^{3}$ residía el 69\% de la población. Los departamentos más poblados eran Francisco Morazán, Cortés, Choluteca y Yoro.

La estructura de la población era joven, el 40.6\% tenía menos de 15 años, la población en edades activas representaba el $55.4 \%$ y solamente el $4 \%$ tenía más de 64 años. El índice de masculinidad alcanzaba el 100.5. El promedio de personas por hogar giraba alrededor de 6.1 personas.

El analfabetismo ${ }^{4}$ alcanzaba el $64.5 \%$ de la población de diez años y más, era más alarmante en el área rural que llegaba hasta el $74.7 \%$ y en el área urbana llegaba a 43.6\%, donde era más desfavorable ese indicador para las mujeres. El nivel educativo de la población era bajo, el 96.2\% de la población era considerada alfabeta, sólo había alcanzado algún grado de la educación primaria.

En las características económicas se estimó la población económicamente activa (PEA) ${ }^{5}$ y la población económicamente inactiva (PEI). La primera asciende a 647,393 personas que representan el 47.3\% del total de la población. La agricultura es la rama de actividad en donde se ubica la mayoría de la PEA (83.1\%), otras ramas con alta representación son la industria manufacturera y los servicios. Las ocupaciones más representativas son los agricultores (82.9\%), producto de la estructura productiva del país, en menor medida hay otras ocupaciones que sobresalen como los artesanos y trabajadores manuales.

\subsection{Preguntas Especiales.}

El censo general de población de Honduras de 1950 además de las preguntas generalmente comunes de todos censos de población como las demográficas, educativas y las económicas, se incluyeron tres preguntas que catalogamos de especiales, porque nos ilustra acerca de algunas características de la vestimenta, el consumo de alimento y de pernocta de las personas, siendo estas una pregunta sobre del uso de calzado, una sobre el consumo de pan de trigo y otra sobre adminículo donde duermen las personas. Específicamente las preguntas fueron formuladas de la siguiente forma:

Pregunta No. 17. Usa calzado.

Pregunta No. 18. Come siempre pan de trigo.

Pregunta No. 19. En que duermen.

Aunque no ubicamos el detalle de las instrucciones de llenado de las preguntas del censo, si encontramos en el detalle de las tabulaciones las categorías de respuesta, para la pregunta 17 y 18 las categorías son "si" y "no" y para la pregunta 19 las categorías son "cama con colchón", "cama con petate", "catre con lona", "hamaca", "tapesco" y "suelo".

En algunas preguntas surgen dudas acerca de algunas categorías, tal es el caso en la pregunta de uso de calzado, especialmente en aquellas personas que usan caites (sandalias) que no sabemos a ciencia cierta si fueron considerados calzados, aunque los elevados niveles de descalzos nos indicaría que no fueron considerados calzados. En el consumo de pan de trigo la pregunta agrega la palabra "siempre" la cual no sabemos el significado de esta definición, si es todos los días, semanas u otra medida de tiempo. El mismo caso sucede en los adminículos

3. Se consideraba como "urbana" es la población de centros poblados donde reside una municipalidad o un distrito y como "rural" las demás. 4. Como "analfabeta" se consideraba quien no sepa leer o escribir..

5. La PEA comprende las personas que trabajan por cuenta ajena recibiendo un sueldo o salarios (empleados), los empleadores, las personas que trabajan por cuenta propia, los miembros de la familia que trabajan sin remuneración directa para el jefe de la familia (trabajadores familiares no remunerados) las amas de casa, estudiantes, etc. Que tienen alguna ocupación remunerada (trabajadores secundarios), los que buscan trabajo (desocupados) y las fuerzas armadas. Queda excluido el trabajo doméstico realizado por los miembros de la familia en su propio hogar. 
para dormir con aquellas camas cubiertas con cuero de vaca que no se sabe en cual categoría se ubican, aunque en esta categoría su frecuencia no sería muy numerosa.

Una limitación importante del análisis de la información es el acceso sólo a los tabulados de las variables, ya que su producción fue manual y esto dificulta relacionarlas con otras variables del mismo censo e individualizar las respuestas de las tres variables seleccionadas para focalizar las respuestas por niveles de bienestar.

\subsubsection{Usa Calzado.}

Los datos muestran como el uso del calzado en la población de Honduras en el año de 1950 era bajo, sólo el 31\% de la población declara usar ese artículo. El uso del calzado es más visible en el área urbana que en el área rural, en el primero la mitad de la población lo usa mientras que en el segundo apenas del 22\% de la población (ver gráfico No. 1).

El departamento de Islas de la Bahía es donde mayormente se usaba calzado en ese año, el 88\% de la población. En sólo tres departamentos del país más de la mitad de la población usaba calzado, Islas de la Bahía, Cortés y Atlántida. En los departamentos de Francisco Morazán y Yoro dicho porcentaje se ubican alrededor del 45\%. En los doce departamentos restantes la población
Gráfico No. 1. Honduras: Población que usa y no usa
calzado, según área de residencia, 1950.

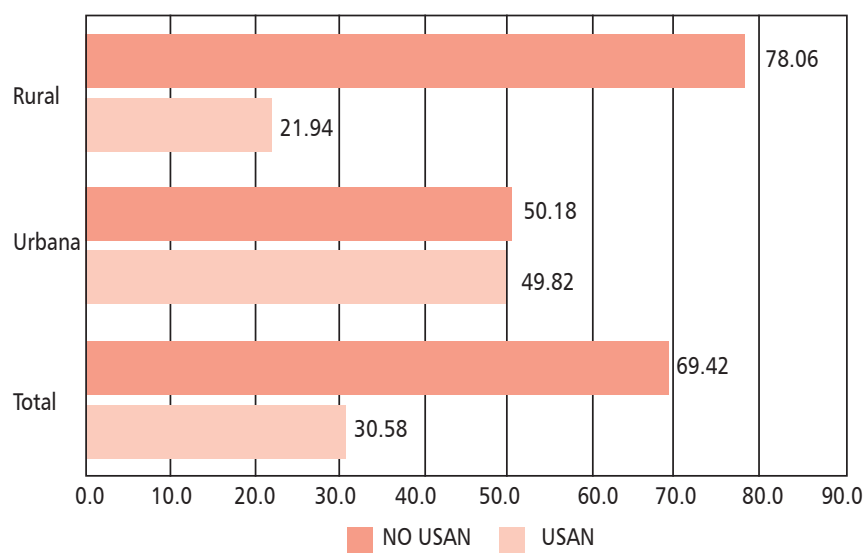

Fuente: Elaboración propia en base a datos de la DGEC, Censo de Población, 1950.

que usaba calzado no superaba el promedio nacional, cerca de un tercio del total. Los departamentos donde el uso del calzado era el más bajo eran Intibucá, Lempira y La Paz, ubicados en la parte centro occidental del país, donde la población de origen indígena Lenca es numerosa. En general, el mayor uso del calzado en la mitad de la centuria pasada era más profundamente un fenómeno urbano, a excepción del departamento isleño que su población rural tenía un porcentaje elevado de uso del calzado y en menor medida Cortés donde superaba ligeramente la mitad de la población rural (ver gráfico No. 2).

Gráfico No. 2. Honduras: población que usa y no usa calzado, según departamento, 1950.

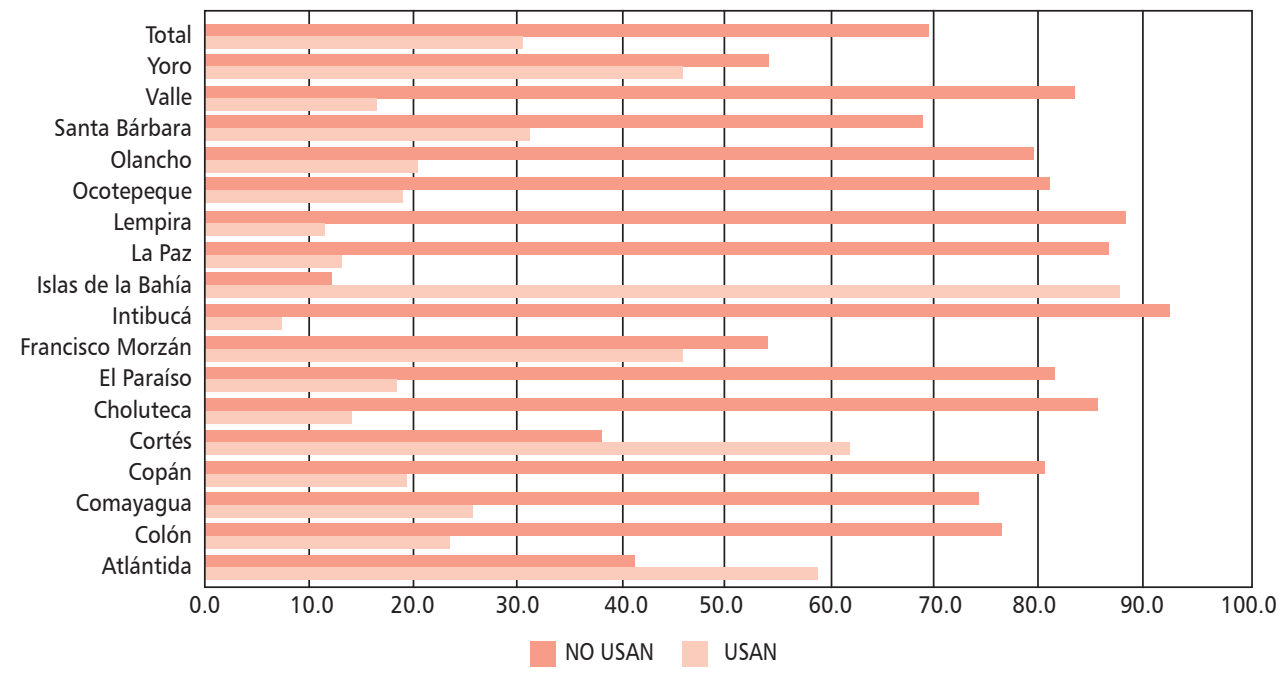

Fuente: Elaboración propia en base a datos de la DGEC, Censo de Población, 1950. 
Los municipios que tienen un mayor uso de calzado en el país, la mayoría están ubicados en la parte norte (a excepción de la capital de la república), en los departamentos de Islas de la Bahía (3), Atlántida (2), Cortés (7) y Yoro (2), (ver cuadro No.1). Los mayores porcentajes de uso, por un lado tienen que ver con el nivel de urbanización, por los mejores niveles de ingreso generados por el incipiente capitalismo generado en el norte de Honduras por las compañías industriales y las bananeras.

Los quince municipios del país donde hay un menor uso de calzado están los ubicados en los departamentos de La Paz (5), Intibucá (5), Francisco Morazán (3), Comayagua (1) y El Paraíso (1). En general, estos municipios son pequeños y están ubicados en la parte centro occidental del país, muchos tienen poblaciones con origen indígena (ver cuadro No. 2).

Cuadro No. 1. Honduras: población de quince municipios con mayor uso de calzado, 1950

\begin{tabular}{|l|c|c|c|c|c|c|}
\hline Municipio & Usan & No Usan & Total & Usan & No Usan & Total \\
\hline Roatán & 4087 & 465 & 4552 & 89,78 & 10,22 & 100,00 \\
\hline Guanaja & 1652 & 261 & 1913 & 86,36 & 13,64 & 100,00 \\
\hline Utila & 1334 & 259 & 1593 & 83,74 & 16,26 & 100,00 \\
\hline La Ceiba & 17355 & 3594 & 20949 & 82,84 & 17,16 & 100,00 \\
\hline Yorito & 2431 & 659 & 3090 & 78,67 & 21,33 & 100,00 \\
\hline San Manuel & 5176 & 2132 & 7308 & 70,83 & 29,17 & 100,00 \\
\hline San Pedro Sula & 38246 & 16022 & 54268 & 70,48 & 29,52 & 100,00 \\
\hline San Francisco de Yojoa & 1791 & 791 & 2582 & 69,36 & 30,64 & 100,00 \\
\hline Distrito Central & 67215 & 32733 & 99948 & 67,25 & 32,75 & 100,00 \\
\hline Puerto Cortés & 14219 & 7218 & 21437 & 66,33 & 33,67 & 100,00 \\
\hline El Progreso & 15436 & 9994 & 25430 & 60,70 & 39,30 & 100,00 \\
\hline Pimienta & 984 & 695 & 1679 & 58,61 & 41,39 & 100,00 \\
\hline Potrerillos & 2396 & 1731 & 4127 & 58,06 & 41,94 & 100,00 \\
\hline Tela & 14448 & 10451 & 24899 & 58,03 & 41,97 & 100,00 \\
\hline San Antonio de Cortés & 2782 & 2268 & 5050 & 55,09 & 44,91 & 100,00 \\
\hline
\end{tabular}

Fuente: Elaboración propia en base a datos de la DGEC, Censo de Población, 1950.

\subsubsection{Consumo de Pan de Trigo.}

El consumo del pan de trigo no ha sido un habito arraigado en la población hondureña, por un lado está la herencia tradicional de uso de la tortilla de maíz que como alimento o bastimento viene de siglos, al mismo tiempo que el trigo no es cultivo muy visible en la campiña nacional, incluso su presencia en el país es propiamente producto de la importación de la harina desde el exterior, inclusive ya en estos años había la existencia de molinos harineros en la zona norte dedicados al procesamiento de este insumo alimenticio.

Producto de la anterior situación los datos reflejan un consumo de pan de trigo de sólo 6\% de la población a nivel nacional, siendo un poco mayor en la zonas urbanas donde se eleva al $15 \%$ y minúsculamente menos del 3\% en la zona rural (ver gráfico No. 3).

A nivel departamental sobresale el consumo de pan de trigo en las Islas de la Bahía, nueve de cada diez personas consumen ese alimento. La relación que este territorio insular ha tenido con el exterior a través del tiempo pudo incidir en este fenómeno, ya que este departamento manifiesta patrones culturales diferentes 
Gráfico No. 3. Honduras: población que come y no come pan de trigo según área de residencia, 1950.

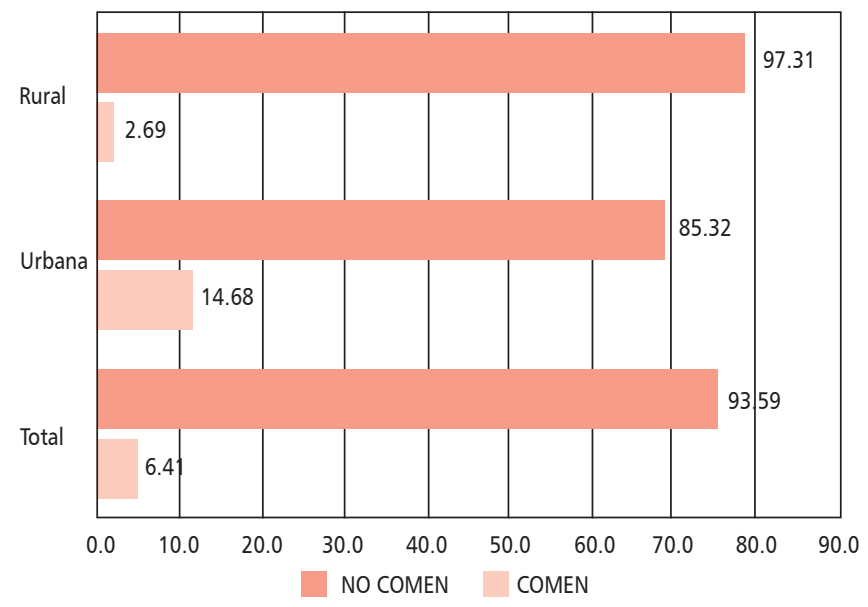

Fuente: Elaboración propia en base a datos de la DGEC, Censo de Población, 1950.

a los de tierra firme, entre ellos ser descendientes de población de origen extranjero, el uso de idioma inglés y otras costumbres. Otros departamentos donde se consume pan de trigo en la mitad del siglo pasado son Atlántida, Francisco Morazán, Cortés y Colón, aunque dicho consumo está entre el 13\% y 25\% del total de la población. Este comportamiento está influenciado por los niveles de urbanización en estos departamentos donde se ubican ciudades importantes, como la influencia desde el exterior. Asimismo, la ubicación de la molinería de la harina de trigo se ubicó en San Pedro Sula y Tegucigalpa y de allí se distribuía al interior en años en donde la infraestructura vial era escasa. En cambio, los restantes doce departamentos los niveles de consumo de pan de trigo son minúsculos, no superan el 2\% (ver gráfico No. 4).

Los municipios de mayor consumo en el país son los tres del departamento de Islas de la Bahía. En la Ceiba hay un consumo relativamente importante, que incluso supera al de las dos ciudades más importantes del país. En general, en los quince municipios de mayor consumo la mitad de ellos son costeros con el Mar Caribe, otros dos que son los más poblados que ubican a la capital gubernamental y la industrial de la nación y el resto son municipios pequeños (ver cuadro No. 3). Suman 195 los municipios en los que se declara que no hay personas que consuman siempre pan de trigo, representan un $72 \%$ del total.

\subsubsection{Adminículos donde Duermen.}

En Honduras la mayoría de la población duerme en cama con petate $^{6}$ en la mitad de siglo pasado, el 74\% y no hay diferencias significativas según el área de residencia de la población. En esta categoría asumimos que se

\section{Gráfico No. 4. Honduras: población que come y no come pan de trigo según} departamento, 1950.

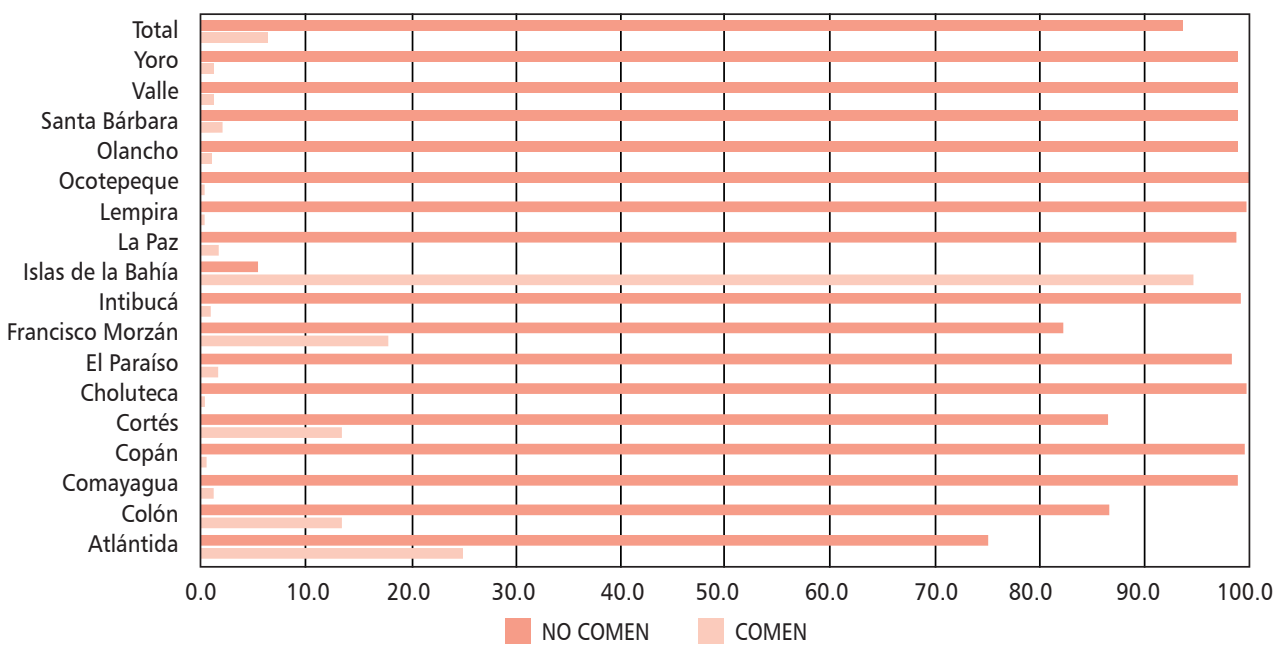

Fuente: Elaboración propia en base a datos de la DGEC, Censo de Población, 1950. 
Cuadro No. 3. Honduras: población de quince municipios con mayor consumo de pan de trigo, 1950

\begin{tabular}{|l|c|c|c|c|c|c|}
\hline Municipio & Comen & No Comen & Total & Comen & No Comen & Total \\
\hline Roatán & 4540 & 12 & 4552 & 99,74 & 0,26 & 100,00 \\
\hline Utila & 1574 & 19 & 1593 & 98,81 & 1,19 & 100,00 \\
\hline Guanaja & 1505 & 408 & 1913 & 78,67 & 21,33 & 100,00 \\
\hline La Ceiba & 12405 & 8544 & 20949 & 59,22 & 40,78 & 100,00 \\
\hline Trujillo & 4631 & 8494 & 13125 & 35,28 & 64,72 & 100,00 \\
\hline Guaimaca & 731 & 1630 & 2361 & 30,96 & 69,04 & 100,00 \\
\hline Distrito Central & 30463 & 69485 & 99948 & 30,48 & 69,52 & 100,00 \\
\hline San Marcos & 725 & 2017 & 2742 & 26,44 & 73,56 & 100,00 \\
\hline Protección & 609 & 1866 & 2475 & 24,61 & 75,39 & 100,00 \\
\hline San Pedro Sula & 11600 & 42668 & 54268 & 21,38 & 78,62 & 100,00 \\
\hline Dulce Nombre de Culmí & 150 & 644 & 794 & 18,89 & 81,11 & 100,00 \\
\hline Omoa & 893 & 3978 & 4871 & 18,33 & 81,67 & 100,00 \\
\hline Puerto Cortés & 3711 & 17726 & 21437 & 17,31 & 82,69 & 100,00 \\
\hline La Masica & 687 & 3358 & 4045 & 16,98 & 83,02 & 100,00 \\
\hline Teupasenti & 1000 & 5451 & 6451 & 15,50 & 84,50 & 100,00 \\
\hline
\end{tabular}

Fuente: Elaboración propia en base a datos de la DGEC, Censo de Población, 1950.

incluyó aquellos adminículos construidos generalmente de madera con un contramarco que es entrelazado con un lazo de mezcal (cabuya) en donde se coloca el petate (ver gráfico No. 5).

En segundo lugar el adminículo más usado es el catre con lona, que es una especie de cama armable o plegable con una cubierta de tela durable. La cama con colchón que sería el adminiculo de mayor estatus social es más visible en áreas urbanas. La hamaca y el tapesco son mobiliarios para dormir más usados en el área rural. El uso de la cama con colchón como adminículo de mayor estatus social se presenta en el departamento de Islas de la Bahía una característica en la mayoría de la población $(88 \%)$, incluso sus tres municipios tenían su

Gráfico No. 5. Honduras: población por adminículos en que duermen según área de residencia, 1950.

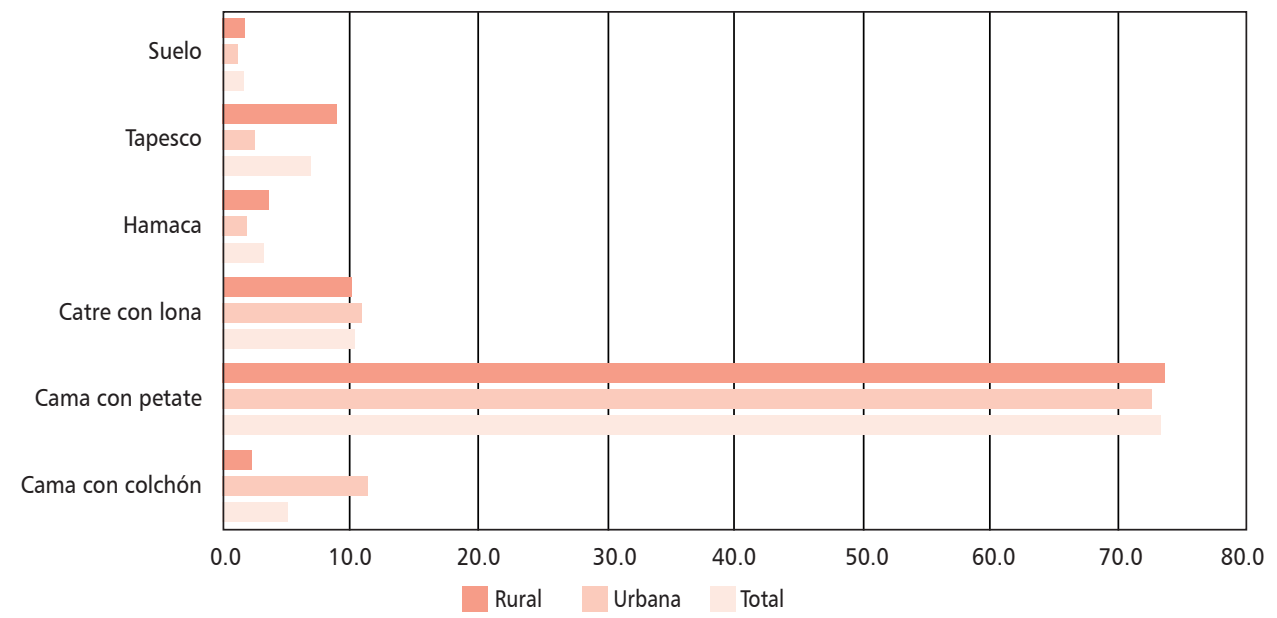

Fuente: Elaboración propia en base a datos de la DGEC, Censo de Población, 1950. 
mayor uso en el país. Los departamentos más urbanizados y en donde se ubican las principales ciudades del país también habían personas que dormían en éstas camas de colchón aunque los porcentajes son bajos, entre el 9\% y 17\% (Ver cuadro No. 4). Seis municipios de Cortés (San Manuel, Omoa, Potrerillos, Puerto Cortés, San Pedro Sula y Choloma), dos de Atlántida (La Ceiba, Tela),
Tegucigalpa, Yuscarán, Teupasenti y la Esperanza estaban entre los quince municipios de mayor uso de cama con colchón, aunque con porcentajes entre un tercio del total y un seis por ciento (ver cuadro No. 5). En los demás departamentos los niveles de uso de este artículo eran bajísimos, incluso habían 196 municipios en donde no se declara la existencia de camas de colchón.

\section{Cuadro No. 4. Honduras: población por adminículos en que duermen según departamentos, en porcentajes, 1950}

\begin{tabular}{|l|c|c|c|c|c|c|c|}
\hline Departamentos & $\begin{array}{c}\text { Cama Con } \\
\text { Colchón }\end{array}$ & $\begin{array}{c}\text { Cama Con } \\
\text { Petate }\end{array}$ & $\begin{array}{c}\text { Catre Con } \\
\text { Lona }\end{array}$ & Hamaca & Tapesco & Suelo & Total \\
\hline Atlántida & 13,0 & 55,3 & 20,9 & 5,1 & 4,3 & 1,4 & 100,0 \\
\hline Colón & 0,0 & 54,3 & 24,1 & 2,3 & 18,3 & 1,0 & 100,0 \\
\hline Comayagua & 0,6 & 83,4 & 7,6 & 0,5 & 7,3 & 0,5 & 100,0 \\
\hline Copán & 0,8 & 80,7 & 1,8 & 0,8 & 15,1 & 0,9 & 100,0 \\
\hline Cortés & 9,6 & 65,6 & 15,5 & 4,6 & 3,1 & 1,6 & 100,0 \\
\hline Choluteca & 0,4 & 83,4 & 1,9 & 5,9 & 7,0 & 1,4 & 100,0 \\
\hline El Paraíso & 2,7 & 73,3 & 13,3 & 2,6 & 7,1 & 1,1 & 100,0 \\
\hline Francisco Morazán & 17,7 & 61,1 & 13,9 & 0,6 & 5,5 & 1,2 & 100,0 \\
\hline Intibucá & 0,6 & 89,1 & 0,7 & 0,1 & 7,1 & 2,3 & 100,0 \\
\hline Islas de la bahía & 88,2 & 4,9 & 3,0 & 1,7 & 1,0 & 1,1 & 100,0 \\
\hline La Paz & 0,5 & 77,9 & 5,3 & 1,3 & 10,3 & 4,6 & 100,0 \\
\hline Lempira & 0,0 & 87,3 & 9,7 & 0,6 & 1,5 & 0,8 & 100,0 \\
\hline Ocotepeque & 0,0 & 82,4 & 4,5 & 0,8 & 11,0 & 1,2 & 100,0 \\
\hline Olancho & 1,0 & 69,6 & 14,2 & 4,7 & 8,3 & 2,2 & 100,0 \\
\hline Santa Bárbara & 0,5 & 80,7 & 7,8 & 4,1 & 5,9 & 1,1 & 100,0 \\
\hline Valle & 0,0 & 88,1 & 0,8 & 8,0 & 2,3 & 0,8 & 100,0 \\
\hline Yoro & 1,4 & 64,7 & 18,8 & 6,3 & 6,5 & 2,3 & 100,0 \\
\hline Total & 5,0 & 73,5 & 10,2 & 3,0 & 6,8 & 1,5 & 100,0 \\
\hline
\end{tabular}

Fuente: Elaboración propia en base a datos de la DGEC, Censo de Población, 1950. 


\section{Cuadro No. 5. Honduras: población de quince municipios con mayor uso de cama con colchón, 1950}

\begin{tabular}{|l|c|c|c|c|c|c|c|}
\hline \multicolumn{1}{|c|}{ Municipio } & $\begin{array}{c}\text { Cama Con } \\
\text { Colchon }\end{array}$ & $\begin{array}{c}\text { Cama Con } \\
\text { Petate }\end{array}$ & $\begin{array}{c}\text { Catre Con } \\
\text { Lona }\end{array}$ & Hamaca & Tapesco & Sulo & Total \\
\hline Guanaja & 96,39 & 0,00 & 0,31 & 0,52 & 0,89 & 1,88 & 100,00 \\
\hline Utila & 93,16 & 0,82 & 0,00 & 6,03 & 0,00 & 0,00 & 100,00 \\
\hline Roatán & 82,97 & 8,44 & 5,23 & 0,70 & 1,45 & 1,21 & 100,00 \\
\hline Distrito Central & 33,75 & 46,28 & 17,72 & 0,33 & 1,16 & 0,75 & 100,00 \\
\hline San Manuel & 23,66 & 24,48 & 27,27 & 19,84 & 1,78 & 2,97 & 100,00 \\
\hline La Ceiba & 21,03 & 50,68 & 17,44 & 4,45 & 5,35 & 1,05 & 100,00 \\
\hline Omoa & 20,18 & 60,58 & 6,22 & 1,77 & 7,74 & 3,51 & 100,00 \\
\hline Yuscarán & 17,03 & 52,50 & 21,07 & 0,73 & 8,66 & 0,00 & 100,00 \\
\hline Tela & 14,94 & 59,32 & 19,92 & 3,56 & 1,19 & 1,06 & 100,00 \\
\hline Teupasenti & 14,77 & 43,26 & 16,59 & 14,25 & 9,72 & 1,41 & 100,00 \\
\hline Potrerillos & 13,03 & 56,59 & 16,20 & 7,78 & 5,98 & 0,43 & 100,00 \\
\hline Puerto Cortés & 11,64 & 64,12 & 14,97 & 3,11 & 4,08 & 2,09 & 100,00 \\
\hline San Pedro Sula & 11,04 & 66,35 & 15,45 & 4,28 & 1,43 & 1,44 & 100,00 \\
\hline Choloma & 9,17 & 79,34 & 4,53 & 3,67 & 2,31 & 0,98 & 100,00 \\
\hline La Esperanza & 8,96 & 80,42 & 7,74 & 0,17 & 2,01 & 0,69 & 100,00 \\
\hline
\end{tabular}

Fuente: Elaboración propia en base a datos de la DGEC, Censo de Población, 1950.

\section{A MANERA DE CONCLUSION}

La mitad del siglo pasado marca el inicio de una nueva perspectiva nacional, recién se salía de una larga dictadura que ensombreció el desarrollo nacional, con lo que cualquier iniciativa gubernamental sería vista como un adelanto, aparte de que las condiciones del país denotaban un atraso que se observaba al detalle compararlo con otros países. La creación de algunas instituciones de la banca estatal, reorganización de instituciones gubernamentales vislumbran el nacimiento del Estado moderno hondureño. Entre estas acciones ubicamos la reorganización de la Dirección General de Censos y Estadísticas y con ello la elaboración del censo de población de 1950, que se suma a la iniciativa regional del censo de las Américas.

El censo hondureño de la mitad del siglo anterior desnuda características poblacionales deprimentes heredadas del estancamiento a que fue sometido el país en las primeras cinco décadas de ese siglo, entre ellas presenta una población que supera el millón trescientos mil habitantes, una baja densidad demográfica, siete de cada diez habitantes residiendo en el área rural, altos niveles de dependencia demográfica, con promedios de seis personas por hogar, dos tercios de ellos analfabetos y los alfabetos con bajos niveles de educación, la población económicamente activa mayormente ubicada en la agricultura en ocupaciones de baja calificación.

Sumada a las anteriores características encontramos en las preguntas que llamamos especiales, poblaciones con bajos porcentajes de uso de calzado, un bajísimo consumo de pan de trigo y un alto nivel de uso de adminículos tradicionales para dormir. Los valores en estas tres interrogantes se manifiestan más deplorables geográficamente en las áreas rurales y aisladas.

\section{BIBLIOGRAFÍA}

- Barahona, Marvin. Honduras en el Siglo XX. Una Síntesis Histórica, Tegucigalpa, Guaymuras, 2005.

- Dirección General de Censos y Estadística. Censo General de Población de 1950, Tegucigalpa, DGE, 1950.

- Checchi, Vicent and Associates. Honduras a problem in economic development, New York, The Twentieth Century Fund, 1959.

- Molino Harinero Sula. Historia. www.molinoharinerosula.com 